\title{
ESTÉTICA E MEMÓRIA DA CANÇÃO DAS MÍDIAS A PARTIR DOS REGISTROS FONOGRÁFICOS DAS CANTORAS DO RÁDIO NOS ANOS 1950
}

\author{
Juliana Marília Coli ${ }^{1}$ \\ Raphael Fernandes Lopes Farias ${ }^{2}$
}

Resumo: Esse artigo analisa como se dá a transmissão de memórias individuais e coletivas por meio das canções e dos processos de performance midiatizada (ZUMTHOR, 1997; 2012; VALENTE, 2013). Escolhemos os anos 1950 por se tratar da gênese da indústria fonográfica brasileira, época a qual temos dedicado nossas pesquisas, elegendo duas cantoras populares do rádio: Juanita Cavalcanti e Dalva de Oliveira. A primeira, de carreira breve, atuou na Rádio Gazeta em meio ao cast lírico; a segunda, de longeva carreira, atuou, sobretudo, em rádios e gravadoras do Rio de Janeiro. Analisando a formação de personas vocais (TAGG, 2012) compreendem-se as influências estéticas, sociais e midiáticas das cantoras, levando em conta a oralidade e as materialidades, e como se criam gostos estéticos e interpretações que marcam períodos e transitam por épocas.

Palavras-chave: Música, rádio, performance, memória, vocalidade.

Abstract: This article analyzes how occurs the transmission of individual and collective memories through songs and processes of mediated performance (ZUMTHOR, 1997, VALENTE, 2013). We chose the 1950s for being the genesis of the Brazilian music industry, at which time we have dedicated our researches, choosing here two popular radio singers: Juanita Cavalcanti and Dalva de Oliveira. The first one, of brief career, appeared in Radio Gazeta in the middle of the lyrical cast; the latter, of a long career, worked mainly in radios and recorders in Rio de Janeiro. Analyzing the formation of vocal personas (TAGG, 2012), the aesthetic, social and mediatic influences of singers are taken into account, considering orality and materialities, and how to create aesthetic tastes and interpretations that mark periods and transit for times.

Keywords: Music, radio, performance, memory, vocality.

\section{Música para as mídias: introdução}

As relações de sentidos presentes na memória de cantoras do período áureo do rádio está inserida em complexo do campo das produções simbólicas (BOURDIEU, 2015) da música gravada ou veiculada por meios de comunicação de massa, e nos serve como um viés de análise de função heurística para entender uma realidade social construída por uma teia de relações mais sutis. ${ }^{3}$

\footnotetext{
${ }^{1}$ Doutora em Ciências Sociais (IFCH/Unicamp). Pós-Doutora em Musicologia (Università degli Studi di Pavia Cremona). Atualmente realiza Pós-doutoramento junto ao Programa de Pós-Graduação em Comunicação da Universidade Paulista com bolsa CAPES e colabora com o Centro de Estudos em Música e Mídia - MusiMid. ${ }^{2}$ Mestre em Comunicação e Cultura Midiática pela Universidade Paulista como bolsista da CAPES. Bacharel em Comunicação e Licenciado em Música. Pesquisador do Centro de Estudos em Música e Mídia.

${ }^{3} \mathrm{~A}$ configuração de tais relações sutis são esclarecidas ainda por Miceli (2005 p. 46): "Logo, poder-se-ia dizer que, no nível da instância simbólica, o sistema de classes sociais metamorfoseia-se em cultura. Esta, por sua vez, instaura as "relações de sentido" em que se naturalizam as relações de classe, tornadas um sistema de diferenças guiados pelo princípio da distinção. No interior desse regime de diferenças, as relações de sentidos encontram-se organizadas em termos de uma hierarquia das legitimidades culturais dominadas pela cultura da classe
} 
De modo especial, as décadas de 1940 até meados de 1960, as rádios contribuem para a franca expansão da difusão musical e das vozes no Brasil. Nesse cenário, destacamos a atuação de duas cantoras: Juanita Cavalcanti e Dalva de Oliveira. Juanita atuou na Rádio Gazeta de São Paulo, tendo sido a primeira cantora popular a ser contratada pelo cast da rádio, que contava com um estúdio/auditório luxuosamente ornamentado como um teatro e com equipamentos de gravação e transmissão de última geração como, por exemplo, microfones especiais capazes de captar vozes líricas e uma orquestra inteira. Dalva, por sua vez, atuou em diversas rádios e gravadoras em sua longa carreira. No período que abordamos, principalmente para a Rádio Nacional, a rádio de maior audiência e elenco do país ${ }^{4}$, e para a gravadora Odeon.

Em meados dos anos 1940, no Brasil - o rádio já consolidado como veículo de comunicação - se abre para uma nova cena musical, marcada pela penetração de gêneros estrangeiros como o bolero, a rumba, o chá-chá-chá e o cool jazz. Os sambas de morro e os arranjos mais contrapontísticos, bem como o canto mais "leve" e cheio de bossa, perderam espaço. As orquestras volumosas, as letras sentimentais e o canto empostado, ornamentado, dominaram o gosto daquele período. (NAPOLITANO, 2005)

Nesse período se dá a conformação das mídias sonoras no Brasil, o auge do rádio e consolidação de uma indústria fonográfica, dentre eles, o bolero e o samba-canção. Paralelo ao franco desenvolvimento da canção, a rádio também se tornou um espaço para a produção e fruição da música denominada "erudita" e também a ópera. ${ }^{5}$

Durante décadas, a Rádio Gazeta, onde trabalhou Juanita Cavalcanti, produziu e divulgou uma extensa e rica programação musical ao vivo, gratuita em horário nobre, na época à noite, mantendo em sua estrutura um ambiente digno dos grandes teatros de ópera, mantendo regentes de orquestra, um coro lírico e um coro popular, uma orquestra sinfônica e uma orquestra jazz sinfônica, arranjadores, cantores solistas, pianistas co-repetidores e copistas, além de uma fonoteca para arquivo e estudo dos músicos. Especialmente, no campo vocal, foi inovadora ao produzir e difundir obras inéditas e óperas inteiras da especificamente

dominante, pelo sistema de ensino da classe dominante e pelo campo de produção erudita tendente a preservar sua autoridade de instância máxima de legitimação e consagração de agentes, obras e receptores”.

${ }^{4}$ A Rádio Nacional, fundada em 1936, disputou a audiência até assumir o primeiro lugar no começo dos anos 1940, época em que passou a fazer parte das Empresas Incorporadas ao Patrimônio Nacional, e passando de empresa privada a repartição pública.

${ }^{5}$ Notamos a importância Rádio Gazeta de São Paulo teve na produção e difusão da ópera lírica entre as décadas de 1940 e 1950 (AUTOR, 2012). 
para o lírico, constituindo-se em forte veículo para a democratização da música naquele momento.

A rádio e o jornal A Gazeta configuravam assim, um potente mecanismo de comunicação e divulgação na cidade de São Paulo, na consolidação da imagem dos artistas e de sua visibilidade comercial para a posterior venda de seus discos, assegurando, ao mesmo tempo, sucesso de bilheteria para o próprio Teatro Municipal de São Paulo.

Em uma dimensão simbólica, a Rádio Gazeta, embora representasse valores de um dado predomínio musical europeu, elegera a construção vocal mitológica do belcanto como estética vocal, em detrimento de outras vocalidades brasileiras, criando ao mesmo tempo, um habitus $^{6}$ vocal que influenciou toda uma geração de cantores e reinventado dentro de uma tradição teatral musical específica, o deslocamento físico da voz. No entanto, aos poucos, esta forma tradicional, influenciaria inevitavelmente a técnica já adaptada aos filtros da tecnologia implicada para a captação da voz.

Cenário parecido era o da Rádio Nacional do Rio de Janeiro, que 1956, ostentava um elenco e uma programação numerosos. É o que nos relata o radialista Renato Murce ${ }^{7}$ (1976), observando um livro comemorativo dos 20 anos da Rádio Nacional. Ali, as 16 novelas, os 10 programas de radioteatro, os 15 programas mistos, os 22 programas de auditório e os 6 especializados contavam com:

112 radioatores e radioatrizes, 76 cantores e cantoras, 99 músicos contratados (só os violinos eram 25), 47 músicos a cachê, 16 músicos dos conjuntos regionais, 10 solistas, 46 locutores, 5 repórteres e 22 produtores. Isso sem contar o pessoal técnico administrativo. Totalizava cerca de 700 pessoas a serviço da emissora. (MURCE, 1976, p.74 - grifo nosso).

Direcionando para questão das cantoras, a performance vocal midiática de grandes intérpretes da rádio, embora metamorfoseada pelos filtros tecnológicos, não prescindiu de uma materialidade que repousa e emana do silenciosa do corpo, enunciando-se como memória de um contexto subjetivo e objetivo, portanto situacional que pressupõe o conhecimento daquilo que se transmite" (RICOUEUR, 2007; ZUMTHOR, 2012).

\footnotetext{
${ }^{6} \mathrm{O}$ conceito de Bourdieu é aqui aplicado ao contexto de constituição dos campo de bens simbólicos da música erudita e, enquanto instrumental conceitual, procura apreender uma dada homogeneidade nos gostos e preferências de grupos e indivíduos produtos de uma mesma trajetória social (BOURDIEU, 2015).

${ }^{7}$ Radialista, responsável por diversos programas de rádio, sendo atribuído a ele o primeiro programa de auditório do rádio, "Papel Carbono". Ajudou a revelar nomes importantes da música Brasileira, como Ary Barroso, Luiz Gonzaga, Ângela Maria, Baden Powell, Dóris Monteiro, Os Cariocas, entre outros.
} 


\section{“Castas Divas" ou "Traviatas"? Juanita no meio lírico; Dalva na "boca do povo"}

No ano de 1954, aos 23 anos, a cantora Juanita Cavalcanti, realizou seu teste de audição na Rádio Gazeta para ser admitida junto ao seu cast exclusivo. Pouco tempo depois, passou a ser chamada de "A estrelinha que dia - a - dia brilha mais". Segundo Matarazzo e Comegno (2013), Juanita teria sido "a primeira cantora popular a ser contratada por uma emissora essencialmente operística" (p. 160).

Também é digno de nota dizer que a soprano Niza de Castro Tank, cantora de ópera que, no papel de Ceci, realizou a primeira gravação de $O$ Guarani no Brasil, com o cast da Rádio Gazeta de São Paulo em 1959, lembra-se de ter ouvido Juanita cantar na rádio, tendo achado a sua voz muito bonita. ${ }^{8}$ Era um modelo de música popular que suscitava na mesma a vontade de cantar outros estilos. ${ }^{9}$.Assim, da atuação de Juanita, em uma emissora que primava pelo universo da música erudita e da ópera, resultou a seguinte manchete na Revista do Rádio de 21/08/1954: "Um broto canta samba no meio das óperas" (apud Matarazzo e Comegno, 2013, p. 160). Aspecto este que vem reforçar o quão impactante foi a sua contratação neste contexto.

Chama a atenção aqui o fato de uma cantora lírica, achar grande beleza de timbre e de impostação vocal em uma cantora popular. O que denota como o universo do rádio e do disco tenha propiciado a difusão não intelectualizada do hibridismo musical brasileiro. As pessoas ouviam todos os estilos de música sem a seletividade de um expert no assunto e podiam ter como modelos vocais vozes que consideravam apenas bonitas.

Embora pouco conhecida, mas com intensa atividade no mercadofonográfico, Juanita Cavalcanti gravou em 1952 pela Continental o baião Мeи limão, mеи limoeiro, do folclore brasileiro, com arranjos de Carolina Pereira e o samba Lamento de uma raça, de Manuel Coelho e Alfredo Godinho. No mesmo ano, gravou de Mário Albuquerque o samba Noite de carnaval, e de Mário Vieira e Guilherme Leite, a toada-baião Oi-lê, oi-lá. Em 1953, gravou a buleria A lua enamorada, de Villajos, Durango e Bolaños, com versão de Juracy Rago, e o samba Tortura sem par, de Ricardo Rangel e Lupicínio Martins. No mesmo ano, gravou o samba João Valentão, do compositor baiano Dorival Caymmi, e o baião Vaidoso, de Poli e

\footnotetext{
${ }^{8}$ TANK, Niza. Entrevista. Campinas, 20/08/2009. Entrevista concedida aos autores.

${ }^{9}$ Idem.
} 
Juracy Rago. Juanita participou do filme Eva no Brasil, cantando o samba-canção Convite ao Rio de João de Barro e Alberto Ribeiro. Este filme, de produção francesa e com direção de Pierre Caron, o longa metragem contou com a participação de grandes nomes do radio brasileiro como Emilinha Borba.

Uma outra cantora de rádio de fama nacional indiscutível, foi Dalva de Oliveira. Nascida Vicentina de Paula Oliveira, Dalva de Oliveira, ao iniciar carreira artística, Dalva estava atrelada ao marido, Herivelto Martins, compositor e cantor. Formavam, juntamente com Nilo Chagas, o Trio de Ouro, conjunto vocal que obteve imenso sucesso nos anos 1940, contratado pela gravadora Odeon, no Rio de Janeiro. Devido às brigas pungentes entre o casal, a separação se deu não apenas no âmbito íntimo, mas no profissional. Dalva saiu do Trio de Ouro e, contrariando as expectativas de Herivelto, a gravadora Odeon a preferiu, com ou sem os demais. Dalva ficou e iniciou sua carreira solo; Herivelto teve de procurar outras gravadoras bem como outros formatos para apresentar suas composições. A contenda entre o casal tomou proporções públicas, criando uma atmosfera de guerra e movendo compositores e letristas para cada um dos lados e mexendo com o imaginário dos fãs. A imprensa deu vazão à troca de acusações do casal, tendo Herivelto, inclusive, assinado uma série de artigos no jornal Diário da Noite, para contar sobre sua vida com Dalva. “A partir daí, o samba-canção começou a dar às pessoas a ilusão de que os artistas estavam se abrindo em música, partilhando suas intimidades publicamente" (CASTRO, 2015, p.96).

Dalva de Oliveira lança seus primeiros sucessos da carreira solo em 1950, os sambas-canções Errei sim, de Ataulfo Alves, e Tudo acabado e o bolero Que Será?, de Marino Pinto - Mário Rossi. Gravou também a marcha Zum-zum, de Paulo Soledade e Fernando Lobo em 1951, e o baião Kalu, de Humberto Teixeira, em 1952. Gravou ainda versões traduzidas de tangos e boleros. A despeito de um certo ecletismo no repertório, comparável ao que vimos em Juanita Cavalcanti, foi no gênero samba-canção que Dalva obteve destaque, encontrando nas características desse gênero na época, sua persona vocal. Dalva também participou de filmes: Maria da praia, 1951, de Paulo Wanderley; Milagre de amor, 1951 e Tudo azul, 1952, ambos de Moacir Fenelon. 


\section{Personas vocais: Marcas Temporais e estéticas da voz}

A voz da canção midiática, mediatizada, aparece como um objeto de estudo particularmente interessante, dada a sua natureza necessariamente híbrida (música, letra), ao qual se agregam outras linguagens: a própria função cênica e teatral (gestos, expressões faciais, atitudes); no plano das linguagens visuais, não apenas o intérprete, bem como sua performance transportam-se para os cartazes, capas de disco, capas de revista etc.); nas linguagens audiovisuais, a teatralidade, moldada de acordo com as tomadas de cena, pontos de vista, de acordo com outros parâmetros. São precisamente estes elementos particulares, combinados de maneiras específicas que determinarão as diferenças entre os intérpretes, as estéticas, os períodos históricos. No caso da música mediatizada, não se pode deixar de considerar as possibilidades que a tecnologia oferece.

O produto que está fonofixado (CHION, 1994) nos discos ou nos fonogramas, juntamente com os outros elementos de performance passam a fazer parte dos critérios de análise: o tempo de existência do fonograma, às vezes é perceptível pelo exercício de escuta. Ainda, somada ao padrão de pronúncia, a emissão vocal, e, mais particularmente, a "mímica vocal” (FONÁGY, 1983) ${ }^{10}$ constituem elementos relevantes, justamente por trazer informações precisas acerca de como se proferiam as performances, na época em que foram os registros foram efetuados e, assim, oferecer elementos para detecção dos elementos que compõem os padrões de gosto.

A voz é singular, única, índice da personalidade tão seguro como as impressões digitais. Pode recolher-se uma amostra precisa dessa voz num lapso de tempo que vai de quarenta e cinco a setenta segundos (CASTARÈDE, 1998, p. 232). Se a voz falar expressa esta identidade, a voz cantada, através de suas particularidades performáticas pode revelar-se na construção de uma nova personalidade, uma personagem vocal.

A persona vocal ou vocal persona foi inicialmente um conceito empregado por TAGG (2012) e posteriormente utilizado na análise do Lied alemão por CONE (1972), que estabeleceu uma estreita relação entre a construção da personagem vocal às determinações estabelecidas pelo compositor. Um dos limites para esta análise está em não considerar o tempo psicológico da criação por parte do cantor e este tempo é psicológico, interior. Uma

\footnotetext{
${ }^{10}$ Mímica vocal designa a gesticulação facial executada ao se pronunciar os fonemas, capaz de ser percebida pela escuta (FONÁGY, 1983).
} 
retórica vocal pode assim ter várias semânticas, mas na música erudita ocidental, ela é sempre determinada pelas regras do compositor.

Mas a persona vocal precisa equacionar um diálogo entre o texto escrito/poético, o texto musical ou a sua relação com a memória/cultura oral e o seu próprio conhecimento na construção de um timbre que possa harmonizar com a voz instrumental (BOUCHARD, 2010).

Compreendemos então que a construção de uma personalidade vocal e de sua performance (ZUMTHOR, 2012), poderá ser relativamente homogeneizada pelos critérios históricos de uma época. E, no caso da música do rádio dos anos 1950, fica evidente que mesmo entre uma cantora lírica como Niza Tank e Juanita Cavalcanti ou Dalva de Oliveira, não há uma hierarquia de valores em suas imagens midiatizadas. Tanto as as "Rainhas do Rádio" Dalva e Juanita, bem como a cantora de ópera Niza Tank, que foi a vencedora do mais importante prêmio da rádio na década de 1950, o Prêmio Roquette Pinto, possuem vestimentas e gestualidades muito parecidas, a formalidade e elegância europeia na vestimenta de uma época, a prosódia da fala e a extensão destes elementos podem, de maneira sutil, revelar-se na voz cantada seja lírica ou popular.

Há de se considerar que uma imagem jamais será descompromissada; ela exerce uma função que justifica a sua existência (promoção de um novo hit, nova turnê, biografia etc.). Após a década de 1950, as extensas coberturas de matérias de jornais, as capas de disco ganham o status de signos de grande relevância, ao adquirir papel semântico: de invólucro ${ }^{11}$, a capa fará parte integrante do projeto criador e identificará o selo da gravadora, o intérprete etc. (AUTOR, 2016).

Ademais, histórias como a do casal Dalva e Herivelto alimentaram inúmeras páginas e colunas de jornais da época. As vozes acusmáticas ${ }^{12}$ do rádio ganhavam fisionomia e corpo através das revistas especializadas e, mais tarde, das capas de disco. No Brasil, títulos como Revista do Rádio, Radiolândia ou outras mais generalistas, como $O$ Cruzeiro, Manchete e tantas outras mostravam as feições e a atitude dessas pessoas que as câmeras captavam de maneira mais ou menos espontânea. Mas essas imagens não podiam abarcar o movimento - algo somente viável no cinema e, posteriormente, na televisão. Nesses termos, a

\footnotetext{
${ }^{11}$ Até o surgimento do longplay, muitas capas eram meros envelopes, em papel pardo; a identificação da época se fazia, unicamente, pelo selo da gravadora e pelo material de que era feito o disco (LAUS, 2006).

${ }^{12} \mathrm{O}$ termo grego, advindo das experiências de Pitágoras, designa o som deslocado de sua fonte, ou seja, o som que ouvimos, mas não vemos quem ou o que o emite. É pertinente também ao termo posterior esquizofonia, utilizado por Murray Schafer, em que a fonte sonora é dissociada da origem via meios eletroacústicos, gravações etc deslocando-se no tempo e espaço. (SCHAFER, 2011 p.364)
} 
imaginação e o imaginário do ouvinte atuavam sob um estímulo muito forte e as canções, por sua vez, “(...) mostram-se como artefatos ou sistemas peritos que os indivíduos e grupos se utilizam para construir sentidos de si, identidades individuais e coletivas" (GIDDENS apud PEREIRA, 2016, p. 29). Temos, então, o que Christian Marcadet (2007) chama de "fato social total".

Adotando o pensamento de Zumthor $(1985 ; 1997 ; 2005)^{13}$, pensamos especificamente no caso da canção midiática, que deve ser entendida como um desdobramento da oralidade tecnicamente mediatizada - modalidade em que se desenvolve a canção das mídias (VALENTE, 2003). O que a caracteriza é a performance é que nela as tecnologias vigentes permitem o apagamento dos vestígios espaciais da voz ao vivo. Perde-se, ainda, a tatilidade e, em grande medida, a "corporeidade, o peso, o calor, o volume real do corpo, do qual a voz é apenas expansão” (ZUMTHOR, 2005, p.19).

Outro aspecto importante a levar em consideração não apenas a distribuição de canais ou a posição em cena, mas também efeitos de reverberação, eco, filtros, microfonia acabam por dar notas diferenciadas no timbre e nos modos de ataque. Importante é ressaltar, ainda que elementos constituintes como o arranjo e a instrumentação, denotam não apenas escolhas estéticas do compositor, mas também seleções feitas por uma extensa comunidade. Reiteramos que um conjunto de estratégias contribui para reforçar um padrão de gosto estético culturalmente pré-estabelecido; assim como promove a eleição de outros- tal ocorre com os modismos.

A música popular neste caso, parece ser mais profícua para este tipo de análise, já que nela, o cantor se exprime através de uma personagem e pode cria-lo sem que as regras de uma semântica rígida seja determinante neste processo. O cantor, na canção pode mudar as regras da música, jogando seja com elementos rítmicos, bem como timbrísticos.

Assim, se pensarmos sob este ponto de vista, podemos dizer que o rádio teve o papel de realizar uma audição primária nas famílias de nossas cantoras, forjando na base, as suas habilidades auditivas e vocais (TOMATIS, 1969).

\footnotetext{
${ }^{13} \mathrm{O}$ autor elaborou um estudo acerca dos níveis de aproximação da linguagem escrita com a oral, classificando a comunicação poética em níveis, de acordo com a maior ou menor aproximação com a escrita, chegando a uma tipologia. Esta que mencionamos é historicamente a mais recente (ZUMTHOR, 1985).
} 


\section{Personas Vocais, Personagens Vocais na História - modelos e matrizes do canto}

É possível afirmar que a construção da persona vocal ocidental forjada pela escola do Bel Canto, durante alguns séculos, foi considerada, sob o ponto de vista formal e escolástico, como a única e correta de colocação da voz ou de vocalidade, desconsiderando toda a tradição anterior ao renascimento, do mundo antigo e de outras culturas e de outras "personas vocais". A criação do mito do Bel Canto, apoiou-se e expandiu-se com a internacionalização da música erudita através da Indústria da Ópera, dos fabricantes de instrumentos, tais como o piano, das editoras e do monopólio da indústria fonográfica e das grandes gravadoras, com as suas respectivas distribuidoras.

Essas indústrias intervêm nas decisões artísticas programáticas dos grandes teatros, influenciando na escolha de certos títulos que se impõem também aos artistas pertencentes a seu star-system, continuamente alimentados por elas. ${ }^{14}$

Por outro lado, as tecnologias de comunicação através da divulgação em massa (rádio e tevê) das vozes líricas antes restritas aos teatros, contribuíram decisivamente para dois fenômenos interligados: a afirmação da música enquanto mercadoria mundial. Caruso ${ }^{15}$ cantava para multidões sem microfone e, quando este surgiu, tratou apenas de fixar a voz, sem alterar sua técnica ou o volume, com a finalidade de multiplicá-la e ampliar os mercados de vendas desta nova mercadoria.

Por falar em mito, do ponto de vista vocal, não poderíamos deixar de citar o caso de Maria Callas, que nos anos 1950 introduziu novos efeitos no modo de cantar, fazendo reviverem a voz da soprano drammatico d'aggilità e papéis havia longa data ausentes dos cartazes (Anna Bolena, Lady Macbeth, Abigaille, da Nabucco etc.), dentre outras mulheres de voz excepcional e grande inteligência musical, como Joan Sutherland e Marilyn Horne. Daí se pode concluir que a voz do século passado, e ainda no nosso século, é predominantemente feminina. ${ }^{16}$

${ }^{14}$ Cf. BONI, 1989, p. 67.

${ }^{15}$ Enrico Caruso foi um cantor lírico italiano, italiano e dono de um aparato vocal único. Caruso manteve estreita relação com a indústria fonográfica, tendo sido um dos primeiros cantores a gravar discos em grande escala.

16 A chamada "revolução Callas", segundo Rodolfo Celesti, assenta-se nos seguintes elementos: "a) il ristabilimento di um fraseggio vario e analítico, teso, attraverso gradazioni d'accento e di colori, non soltanto a realizzare i segni d'espressione dei compositori, ma a dare al significato delle parole il maggior risalto psicológico attraverso um gioco sotillissimo di contrasti chiaroscurali e di sfumature - e questo sai Che si trattasse d'un recitativo, Che di un'aria o d'un duetto; b) il ritorno al vero virtuosismo, Che consiste nel dare espressione allá coloratura e nel rivalutarne quelli che Rossini definiva come 'gli accenti nascosti'; c) la riproposta di um 'cantabile', preromantico o romântico che fosse, eseguito com morbidezza di suono, purezza di 
A questão da construção do mito no canto também se relaciona ao significado de primadonna próprio do teatro lírico, como a mulher caprichosa, que não aceita todas as regras da profissão e que as infringe, como conquista de um status individualista. Estes elementos apresentam o mito da primadonna, neste raciocínio, como função positiva do "explorador quando a música clássica está em condições de conquistar um novo público" (RATTALINO apud ENCICLOPEDIA DELLA MUSICA, 2001, p. 916).

Fenômenos como Caruso, que está intimamente associado ao rádio e à indústria discográfica, e Callas, que se relaciona, além da discografia, com a tevê, mostram como a relação entre a fama e os meios de comunicação não impõe limites no que diz respeito à expansão de seu mercado, alimentando e desenvolvendo uma lucrativa cadeia de informações que se nutre, também, da intimidade de seus ídolos, por meio de jornais e de revistas, dos diversos programas de televisão e suas variações. ${ }^{17}$

A indústria fonográfica possibilita que uma obra seja gravada, com o mínimo de margem de erro, sem que tenha sido estreada em algum teatro, representando quase que um teste, como quando uma mercadoria qualquer é experimentada antes de ser realmente colocada no mercado. Com a difusão de toda forma de gravação e registro vocal, a música torna-se "efetivamente uma mercadoria em seu sentido pleno, intercambiável com a mercadoria universal, o dinheiro" (DALMONTE, 2001 p. 286).

\section{Vozes que (en)cantam: considerações finais}

Segundo Castarède (1988) e Tomatis (1969), a voz está próxima do puro afeto, sua comunicabilidade possui um duplo código - "o dito e não dito", na qual está presente aspectos eminentemente psicológicos, como a pulsão irracional fala daquilo que não queremos demonstrar (FONÁGY, 1983), remontando uma audição primária, uterina, a voz da mãe.

legato, continuità di cavata, abbandono patético o elegiaco, intensità di effusione lírica; d) la rinascita di tipi vocálico-psicologici del melodramma neo-classico e protoromantico travisati o annullati dalle prassi interpretative del tardo Romanticismo e del verismo: la Regina, la sacerdotessa, la maga" (DALMONTE apud ENCICLOPEDIA DELLA MUSICA, 2001, pp. 299-300).

${ }^{17}$ Neste contexto as aparições regulares de cantores de ópera na televisão, conferem a estes cantores, já conhecidos nos palcos e dos discos, maior popularidade e visibilidade. Notamos aqui o caso exemplar da soprano Maria Callas que, similarmente ao caso de Dalva de Oliveira, teve as suas aparições midiáticas associadas a polêmicas em torno de sua vida íntima e amorosa com Onassis, que ajudavam a alimentar esta mistura de mulher mito e poderosa através da versão oposta, que buscava a exposição constante de suas fragilidades. 
Resta considerar que, para além dos aspectos da pulsão e do jogo midiático da Indústria Cultural que alguns cantores com características específicas marcaram a história da música, enquanto outros tecnicamente perfeitos não.

\begin{abstract}
(...) a construção de uma persona musical e midiática, as formas de entoar e dizer as canções, o tom, o timbre das vozes as repetições de acordes e introduções que se tornam velhas conhecidas dos ouvintes e as estórias narradas nas letras acionam mecanismos de identificação e projeção (MORIN 1975) ou mesmo formas de interpelação (FRITH, 1996; VILA, 1996) no público, trazendo formas de colocar-se no lugar deste "eu" que canta, compartilhando o protagonismo das alegrias e infelicidades do amor, das relações e da vida. (PEREIRA, 2016, p.30).
\end{abstract}

Assim, se a história de vida de nossas cantoras incide sobre as suas vocalidades moldando suas vozes e os seus corpos, posto que, ambos são historicamente determinados, podemos inferir que não existem vozes e personas vocais sem corpos e estes. Como produtos de uma história, suas performances que são, ao mesmo tempo, marcadas e construídas por subjetividades e fatores sociais, criam a personagem vocal midática.

É então partir do conceito de performance, no contexto histórico e midiático, que compremos que uma personagem vocal se cria por canais poéticos: timbre, letra, imagem, gesto, tecnologia etc. E, nesse sentido, a memória - no caso, musical - se constrói por esses mesmos canais: vocais, materiais e circunstanciais.

\title{
Referências
}

BONI, M. (org.). L'economia dietro il sipario. Turim: EDT, 1989.

BOURDIEU, Pierre. A economia das trocas simbólicas (Introdução, organização e seleção de Sérgio Miceli), 8 a edição. São Paulo: Perspectiva, 2015.

BOUCHARD, V. Le personnage vocal. Une exploration pluridisciplinaire du chant dans la musique populaire. Università de Montreal, Departament de musicology, 2010.

CASTARÈDE, M. F. A voz e seus sortilégios. Lisboa: Editorial Caminho, 1988.

CASTRO, R. A noite do meu bem - A História e as histórias do samba-canção. São Paulo: Companhia das Letras, 2015.

CHION, M. Musiques: médias et technologies. Paris: Flammarion, 1994.

CONE, E. T. The composer's voice. Berkeley: University of California Press, 1972. 
DALMONTE, R. "Voci”, in Enciclopedia della Musica. Turim: Einaudi, 2001.

FÓNAGY, I . La vive voix: essais de psycho-phonétique. Paris: Payot, 1983.

HUFFINGTON, A. Maria Callas, a mulher por trás do mito. São Paulo: Cia das Lestras, 1996.

LAUS, Egeu. A história do design das capas de disco no Brasil -parte I. Especial para o Jornal Musical. Rio de Janeiro: 26 de dezembro de 2006.

MARCADET, C. "Fontes e recursos para a análise das canções e princípios metodológicos para a constituição de uma fonoteca de pesquisa”. In: VALENTE, H. (org.). Música e mídia: novas abordagens sobre a canção. São Paulo: Via Lettera/FAPESP, 2007.

MATARAZZO, T. COMEGNO, V. A Dinastia do Rádio Paulista. Bragança Paulista: ABR Editora, 2013.

MICELI, S.. A noite da madrinha. São Paulo : Companhia das Letras, 2005.

MURCE, R. Bastidores do rádio. Rio de Janeiro: Imago, 1976.

NAPOLITANO, M. História e Música. Coleção História e Reflexões. Belo Horizonte:

Autêntica, 2005.

PEREIRA, S, L; Ulhôa, M. (orgs.) Matrizes e mediações das canções românticas na América Latina. In Canção Romântica: intimidade, mediação e identidade na América Latina. Rio de Janeiro: Folio, 2016

RICOEUR, P. A memória, a história, o esquecimento. Campinas: Editora da Unicamp, 2007.

RATTALINO, P. "Le primedonne: cantanti, strumentisti, diretori d'orchestra”, in

Enciclopedia della Musica. Turim: Einaudi, 2001.

TANK, N. Entrevista. Campinas, 20/08/2009. Entrevista aos autores.

TOMATIS, A. El oído y el linguaje. Barcelona: Molíns de Rey, 1969.

TAGG, P. Music's Meanings: a modern musicology for non musos. New York \&

Huddersfiekd: Mass Media Music Scholars'Press, 2012. Disponível em:

http://quaderna.org/philip-tagg-musics-meanings-a-modern-musicology-for-non-musos-newyork-huddersfield-mass-media-music-scholars-press-2012. Acesso em 20 de janeiro de 2018. VALENTE, H. A. D. As vozes da canção na mídia. São Paulo: Via Lettera/ FAPESP, 2003. ZUMTHOR, P. Introdução à poesia oral. São Paulo: Hucitec; Educ, 1997. Escritura e nomadismo. São Paulo, Ateliê, 2005. Performance, recepção, leitura. São Paulo: Cosac-Naify, 2012. 